\title{
Designing User Interaction with Linked Data in Historical Archives
}

\author{
CLÁUDIA GUEDES, INESC TEC and Faculty of Engineering, University of Porto, Portugal \\ BRUNO GIESTEIRA, INESC TEC and Faculty of Fine Arts, University of Porto, Portugal \\ SÉRGIO NUNES, INESC TEC and Faculty of Engineering, University of Porto, Portugal
}

\begin{abstract}
In this article, we present solutions to visualize and interact with linked data in historical archives considering three different scenarios: search, individual record view, and creation of relationships. The created solutions were designed using nonfunctional mockups and were based on the CIDOC-CRM model, a model created and applied in the museums community liable to be extended to other cultural heritage institutions, being our solutions an application of this model to archives. A sample of 20 archival professionals was selected to evaluate the elements included in the proposed solutions. The evaluation sessions consisted in structured interviews supported by an introductory video and a survey. The think-aloud protocol was applied during the sessions. We conducted both a quantitative and qualitative analysis to the collected answers. From this analysis, we conclude that the majority of the participants showed great receptivity to the solutions presented and recognized many benefits in the application of linked data. Our contributions also include an exploratory study of some existing linked data systems, giving particular attention to their visualization and interaction modes.
\end{abstract}

CCS Concepts: • Information systems $\rightarrow$ Semantic web description languages; • Applied computing $\rightarrow$ Digital libraries and archives; $\bullet$ Human-centered computing $\rightarrow$ User studies;

Additional Key Words and Phrases: Linked data, semantic web, archives, user interface design, user interaction

ACM Reference format:

Cláudia Guedes, Bruno Giesteira, and Sérgio Nunes. 2022. Designing User Interaction with Linked Data in Historical Archives. f. Comput. Cult. Herit. 15, 3, Article 43 (September 2022), 22 pages.

https://doi.org/10.1145/3485731

\section{INTRODUCTION}

Since its inception, the World Wide Web has evolved to become a global data space where data is structured to be understood by both humans and machines. This generation of the Web is known as Web 3.0 [24], Web of Data, or Semantic Web. The term Linked Data (LD) was introduced in 2006 by Berners-Lee to refer to a set of best practices to publish and interlink structured data on the Web, being essential to build the Semantic Web [3]. The

This work is financed by National Funds through FCT - Foundation for Science and Technology I.P., within the scope of the EPISA project DSAIPA/DS/0023/2018. This project was proposed by INESC TEC - Institute for Systems and Computer Engineering, Technology and Science and has as partners the University of Évora and DGLAB - Direção-Geral do Livro, dos Arquivos e das Bibliotecas, its public administration partner. A word of appreciation to DGLAB on behalf of the team of professionals led by Dr. Francisco Barbedo for the strict collaboration and enthusiasm in the search for new solutions in order to promote the evolution of the Portuguese archives.

Authors' addresses: C. Guedes and S. Nunes, INESC TEC and Faculty of Engineering, University of Porto, Rua Dr. Roberto Frias, $4200-465$ Porto, Portugal; emails: \{up201505409, sergio.nunes\}@fe.up.pt; B. Giesteira, INESC TEC and Faculty of Fine Arts, University of Porto, Avenida Rodrigues de Freitas, 265, 4049-021 Porto, Portugal; email: bgiesteira@fba.up.pt.

Permission to make digital or hard copies of all or part of this work for personal or classroom use is granted without fee provided that copies are not made or distributed for profit or commercial advantage and that copies bear this notice and the full citation on the first page. Copyrights for components of this work owned by others than ACM must be honored. Abstracting with credit is permitted. To copy otherwise, or republish, to post on servers or to redistribute to lists, requires prior specific permission and/or a fee. Request permissions from permissions@acm.org.

(c) 2022 Association for Computing Machinery.

1556-4673/2022/09-ART43 $\$ 15.00$

https://doi.org/10.1145/3485731 
value of LD is increasingly being recognized in the cultural heritage sector, particularly in Galleries, Libraries, Archives, and Museums (GLAM), since these institutions share the mission of safeguarding, preserving, and providing access to their artifacts. In addition, they share the same interests in the use of LD [27]. However, the use of LD in these institutions can have different implications given their particular characteristics. In the case of archives, for instance, the resources are exclusive and described in aggregations. As such, it becomes necessary to review the best practices regarding the use of LD in libraries and museums prior to their application in archives [22]. The growth in the use of LD by these institutions poses some challenges in terms of visualization and interaction, since cultural heritage data is characterized by its high level of complexity, heterogeneity, semantic richness, and interconnectivity.

Nowadays, we can find several LD systems applied to different domains and studies focused on visualization tools and techniques for LD. Cultural heritage institutions already offer user interfaces built using Semantic Web technologies; however, archives are still beginning to explore its full potential. LD brings advantages not only to the archivists responsible for the production of content but also to the public that consumes this same content. The adoption of LD in the archival process reveals an evolution in the way archival descriptions are made and not a change in their definition. LD proves to be an effective approach to improve archival descriptions by increasing its granularity and interoperability, allowing archivists to "use and incorporate the information of other linked data providers into their local description," making them "more complete, and more value-added" [15]. LD also promises to increase access to information, improve the information search by offering straight answers to users' search queries [21], and promote the inference of new knowledge through the semantic relationships established between the data.

Guided by the motivation of the lack of standard solutions to interact with LD in end-user interfaces [6], we designed and evaluated solutions for the archival domain that allow archival professionals to interact with LD, based on the International Committee for Documentation-Conceptual Reference Mode (CIDOC-CRM) model. The solutions presented and evaluated here are focused on three interaction scenarios: search, individual record view, and defining relationships between nodes.

Following this initial outline and presentation of the problem in the context of the use of LD in cultural heritage institutions, particularly in archives, the remainder of the article has the following structure. In Section 2, we provide a literature review on the topics of LD, CIDOC-CRM and RiC (Records in Contexts) standards, and interaction design patterns. In Section 3, we present the methodology followed in the design and evaluation of the work. The work developed is presented in Section 4 and the evaluation process is described in Section 5. An analysis of the results is presented in Section 6 and, finally, the overall conclusions can be found in Section 7.

\section{LITERATURE REVIEW}

In this section, we start by presenting some existing LD systems that were analyzed taking into account our scenarios of interest. Then, we highlight some of the main characteristics of the CIDOC-CRM and RiC standards and we finish by addressing the topic of interaction design patterns and its relevance to the design of user interfaces in order to ensure better design solutions and user experiences.

\subsection{Linked Data Systems}

This section is dedicated to the study of existing LD systems giving particular attention to its interfaces. Taking into account the richness and heterogeneity of the data concentrated in historical archives and the challenges raised regarding the search, the identification of elements to include in the individual views, and the creation of relationships, we defined the three interaction scenarios already mentioned as a starting point for the analysis of existing LD systems. Specifically, the three scenarios defined were search (i.e., types of search approaches, ways to present search suggestions, and ways to visualize search results); individual record view (i.e., interface 
elements used in the individual views of each resource); and create relationships (i.e., interaction solutions to establish relationships between resources).

Of the six systems analyzed, some of the common design options and features found in them are described next. This list includes, in this order, four applications of the CIDOC-CRM model, one application of the RiC standard, and an intelligent graph platform, given its relevance for the creation of relationships. In the end of this section, we include mentions to additional systems, as we also consider them relevant initiatives in the application of LD in different domains.

ResearchSpace. ResearchSpace [19] is an open source collaborative project envisioned by the Andrew W. Mellon Foundation, a major funder of humanities and cultural heritage research. This platform, presented in 2013 [23], was designed at the British Museum and has applications in several areas, such as archaeology, art history, and history of science. Regarding the search scenario, one of the key features offered by this platform is the structured search where the user can select different search criteria iteratively through distinct interface components. Searches can involve different entities: "Thing," “Actor," "Place," "Time," "Event," and "Concept." The search results can be visualized in different ways: in a timeline, through different graphical representations (line, bar, radar, pie, and donut charts), in a table, or even on a grid. In the individual view there is a section with the metadata associated with the resource extracted from the British Museum knowledge graph and a section for community contribution. This platform presents an interface with three buttons that allow one to visualize the outgoing and incoming statements, access to a graph view and to a diagram where the user can build a sequence of statements related to the resource in question and discover how it relates to other resources.

British Museum. The British Museum is a cultural heritage institution that uses an OWL (Ontology Web Language) implementation of CIDOC-CRM called the Erlangen CRM [26] to provide access to its online collection in a machine-readable format [20]. For the search scenario, this interface offers the possibility to search for objects related to a specific person, organization, or place, to search by object type or museum number, or to search by all the mentioned fields. The simple search box will present related suggestions, being each one associated with the category to which it belongs and the number of results that would be retrieved if the search was performed. Search results can be displayed in a grid or list. The individual view of each search result is divided into two resizable sections: one for the metadata associated with the resource and another for the image. The metadata section has available some links in certain information or properties about a resource that takes the user to the respective individual view which contains specific information and related objects, distributed in two tabs.

Arches. Arches [25] is a web-based open source software for the management of cultural heritage data, which can be freely used by interested institutions. This platform was developed using two CIDOC standards: CIDOCCRM and the draft of the CIDOC International Core Data Standard for Archaeological and Architectural Heritage [5]. Arches presents a rich interface that explores the three scenarios under study. For the search scenario, Arches offers a simple search showing resources, relationships, metadata, and other suggestions: a map view, a time filter or time wheel, an advanced search by facets, and a graph view where it is possible to visualize related resources. Exploring the individual record view scenario, we highlight the presence, in some cases, of an interactive map, specific metadata fields associated with the resource in question, and a section dedicated to related resources. Regarding the creation of relationships scenario, Arches offers a table view accessible from the graph view. The interface presents two tabs to facilitate switching between the views, being the creation of new relationships is made in the table view. The respective line of the table will be updated and, when returning to the graph view, the user will see the relationship created directly in the graph.

ARIADNE. The ARIADNE [2] project aggregates data infrastructures for archaeological research in a single portal. This platform works with an extension of CIDOC-CRM. In regard to the search scenario, ARIADNE offers a simple search with facets and the search suggestions are supported by multilingual terms. This portal also 
Table 1. Tools Overview

\begin{tabular}{|c|c|c|c|c|c|c|}
\hline & ResearchSpace & British Museum & Arches & ARIADNE & Sparnatural & Linkurious \\
\hline \multicolumn{7}{|l|}{ Search approaches } \\
\hline Simple & & $\checkmark$ & $\checkmark$ & $\checkmark$ & & \\
\hline Structured & $\checkmark$ & & & & $\checkmark$ & \\
\hline Advanced & & & $\checkmark$ & & & $\checkmark$ \\
\hline \multicolumn{7}{|c|}{ Visualization of search results } \\
\hline List & & $\checkmark$ & $\checkmark$ & $\checkmark$ & $\checkmark$ & \\
\hline Grid & $\checkmark$ & $\checkmark$ & & & & \\
\hline Map & & & $\checkmark$ & $\checkmark$ & & \\
\hline Other & $\checkmark$ & & & $\checkmark$ & & \\
\hline \multicolumn{7}{|l|}{ Related resources } \\
\hline Table & $\checkmark$ & & $\checkmark$ & & & \\
\hline Semantic network & $\checkmark$ & & $\checkmark$ & & & $\checkmark$ \\
\hline Links & $\checkmark$ & $\checkmark$ & $\checkmark$ & $\checkmark$ & & \\
\hline
\end{tabular}

offers the possibility to browse the catalog through three distinct starting points: "Where" (map based browsing), "When" (timeline browsing), and "What" (subject browsing) [18]. The search results are shown in a list and can be refined through a dynamic set of filters. For the individual record view scenario we highlight the use of sections that present geographically and thematically similar resources.

Sparnatural. Sparnatural [10] is a free and open source JavaScript component that allows the visual construction of SPARQL queries. It was developed within the scope of the OpenArchaeo project, being used for navigation in archaeological resources. Sparnatural was highly inspired by the structured search offered by the ResearchSpace platform. Therefore, the search scenario includes the structured search which offers a variety of ways to select the values corresponding to the search criteria, such asautocomplete fields, dropdown lists, simple string values, date ranges, or no selection. The search results are listed below the search area and are constantly being updated according to the user interaction. It is also possible to see the SPARQL code being generated as the queries are built. The requests are sent to DBpedia, which contains the information sources.

Linkurious. Linkurious [12] is an intelligent graph platform founded in 2013 which allows the search and visualization of large graph databases like Neo4j and AllegroGraph. Regarding the creation of relationships scenario, this platform offers a mechanism in which the creation of relationships is made through the graph, containing the following elements: source and target nodes, changing the direction of the relationship, the type of the relationship, and respective properties.

Table 1 provides a uniform view of some aspects covered in these tools.

Many other initiatives revealed the investment made in several fields in the application of LD, which were properly explored taking into account the defined scenarios. Thus, several interaction solutions and information visualization techniques were confronted, having been chosen as those that met our user requirements, also contemplating some innovative solutions presented by systems that adopt different description standards, namely, CIDOC-CRM and RiC. Thus, it was possible to incorporate some alternative elements inspired by existing LD systems and to collect opinions regarding their usefulness for the professional activities of our end users. Some examples are Heritamus, Gnoss, Rijksmuseum, LiLa, Finnish National Gallery, National Archives of the Netherlands, Europeana, Bibliotèque Nationale de France, LEI (Legal Entity Identifier), German Digital 
Library, The National Gallery, Doremus, Yale Center for British Art, The Metropolitan Museum of Art, Muse, LodLive, LD-VOWL, SNAC, Piaaf, and Memobase. For the creation of relationships, specifically the addition of references was based on the mechanism presented by the Wikidata platform.

\subsection{The CIDOC-CRM Standard}

The CIDOC Conceptual Reference Model is an official ISO standard (ISO 21127:2014) since the end of 2006, and is known as "a formal ontology intended to facilitate the integration, mediation, and interchange of heterogeneous cultural heritage information" [11]. It was created in the context of museums, but there are already applications of the model in other areas, mostly in galleries and libraries. This model is suitable for the new technological era marked by the Semantic Web and LD, facilitating the search, sharing and linking of information in cultural heritage institutions such as archives, libraries, and museums.

CIDOC-CRM offers a set of entities and properties. Entities have properties that identify each established relationship and both follow a hierarchical structure. Taking into account the notations adopted by this standard, each entity is represented by the prefix "E" and each relationship is represented by the prefix "P," both followed by a numeric code. The main entities of the CIDOC-CRM considered relevant for the archival domain are the Event (“E2 Temporal Entity"), Actor ("E39 Actor”), Place ("E53 Place”), Time-Span (“E52 Time-Span”), Physical Thing ("E18 Physical Thing”), and Conceptual Object ("E28 Conceptual Object").

\subsection{The RiC Standard}

Records in Contexts (RiC) is an archival description standard proposed by the International Council on Archives (ICA) [13] that began its development in 2012 with a group of specialists from 13 countries. This archival standard intends to implement the International Conceptual Model of Archival Description RiC-CM, in order to integrate the four existing archival standards: ISAD(G) (General International Standard Archival Description), ISAAR(CPF) (International Standard Archival Authority Records-Corporate Bodies, Persons, and Families), ISDF (International Standard Description of Functions), and ISDIAH (International Standard Description of Institutions with Archival Holdings) [16]. The RiC archival description standard is divided into two parts: the abstract conceptual model and the ontology.

The abstract conceptual model, referred to as RiC-CM, aims to standardize the concepts used within the professional community and facilitate information sharing within its members. The description entities are the objects that are used to describe and connect information from different information systems and are listed in Table 2. The ontology, referred to as RiC-O, is the technical counterpart of the RiC-CM, and defines the vocabulary and rules to be applied to digital archival metadata and enables the publishing of RDF datasets as LD. RiC-O will facilitate the representation of archival collections spanning information systems of different institutions, enabling data reusability, and seeks to support data preservation by standardizing the descriptive metadata. The adoption of RiC-O requires knowledge of the commonly used technologies in the Semantic Web world: XML (Extensible Markup Language), RDF, and related technologies, such as the SPARQL query language, OWL, and databases for managing and publishing RDF datasets, such as GraphDB.

\section{METHODOLOGY}

Our research followed the User-Centered Design (UCD) methodology, which focuses on building applications that meet users' needs and expectations by involving them in the different phases of the design process. The implementation of this methodology leads to applications that ensure good usability and user experience [17]. In order to adopt this methodology, we divided our work into four distinct phases: (1) Understanding the context of use; (2) specifying the user requirements; (3) designing the solutions, and (4) evaluating the solutions. It is important to note that this methodology was readjusted due to the COVID-19 pandemic. Initially, we had 
Table 2. RiC-CM Entities (Adapted from Llanes-Padrón

and Pastor-Sánchez [16])

\begin{tabular}{ll}
\hline RiC Entity & Denomination \\
\hline RiC-E1 & Record \\
RiC-E2 & Record Component \\
RiC-E3 & Record Set \\
& Agent \\
& Delegate Agent (subtype of Agent) \\
RiC-E4 & Person (subtype of Agent) \\
& Group (subtype of Agent) \\
RiC-E5 & Occupation \\
RiC-E6 & Position \\
RiC-E7 & Function \\
RiC-E8 & Function (Abstract) \\
RiC-E9 & Activity \\
RiC-E10 & Mandate \\
RiC-E11 & Documentary Form \\
RiC-E12 & Date \\
RiC-E13 & Place \\
RiC-E14 & Concept/Thing \\
\hline
\end{tabular}

planned to conduct interviews with end users at their own workplace, including direct observation of their interaction with the current archival management system. We had also planned to apply participatory design techniques involving users in workshops, allowing them to also participate in the design of possible solutions. In this context, all interviews conducted to assess the created solutions had to be done remotely. Considering the limitations imposed by this pandemic, and the impossibility to accomplish such activities, we gathered documentation related to user requirements from different working groups involved in the EPISA project and interviews carried out by one of the DGLAB [9] members with the archival practice community, but also with the community of conservation and restoration and support transfer.

During the design process, in phase 3, we adopted several design patterns proposed for user interface design. Design patterns are proven solutions that can be replicated to solve common design problems. These patterns aim to impose a greater pace in the design phase of new projects, minimizing the time and effort employed, ensure better design solutions, promote better communication between designers and developers, as well as instruct designers. Interaction design patterns can be translated into better user interactions, being associated not only with architectural aspects (related with the structure and organization of the elements), but also with dynamic behaviors and changes in elements in order to adapt to the user interactions [8]. Tidwell groups design patterns into 11 categories [28]. The design patterns adopted in the interface design are identified in Table 3, which also contains a brief description of each and its specific applications. 
Table 3. Interaction Patterns Adopted in the Interface Design

\begin{tabular}{|c|c|c|}
\hline Pattern & Description & Specific Application \\
\hline Alternative Views & $\begin{array}{l}\text { Allows the user to choose among alternative views } \\
\text { that are significantly different. }\end{array}$ & Semantic network view and table view. \\
\hline Modal Panel & $\begin{array}{l}\text { The user has to perform some specific task or simply } \\
\text { leave the modal to continue browsing the website. }\end{array}$ & $\begin{array}{l}\text { Visualization of the details of a relationship } \\
\text { and creation of relationships. }\end{array}$ \\
\hline Breadcrumbs & $\begin{array}{l}\text { Intends to show the user each level of the website } \\
\text { hierarchy up to the current page. }\end{array}$ & $\begin{array}{l}\text { Located in the upper left corner of all pages } \\
\text { except the homepage. }\end{array}$ \\
\hline Visual Framework & $\begin{array}{l}\text { Applied in the design of the different pages, which } \\
\text { use the same layout and stylistic elements in order } \\
\text { to facilitate navigation and use. }\end{array}$ & All pages. \\
\hline Titled Sections & $\begin{array}{l}\text { Separate sections of content visually, facilitating the } \\
\text { search for information. }\end{array}$ & Some sections in the individual views. \\
\hline Module Tabs & $\begin{array}{l}\text { The content modules are separated by tabs, only } \\
\text { being visible one at a time. }\end{array}$ & $\begin{array}{l}\text { Visualization of search results and details of a } \\
\text { relationship. }\end{array}$ \\
\hline Accordion & $\begin{array}{l}\text { Arranges the content modules vertically in a stacked } \\
\text { list of panels that can be expanded or collapsed } \\
\text { independently of each other. }\end{array}$ & Advanced search and individual views. \\
\hline Row Striping & $\begin{array}{l}\text { Facilitates the reading of data in tabular format through } \\
\text { the use of alternating background colors in the table } \\
\text { rows. }\end{array}$ & Table view. \\
\hline Pagination & $\begin{array}{l}\text { Allows the user to browse several pages of content } \\
\text { without being overwhelmed. }\end{array}$ & Search results and table view. \\
\hline Tree Table & Items are organized in a hierarchy. & $\begin{array}{l}\text { Hierarchical browsing and "Hierarchy" section in } \\
\text { the individual view of a record. }\end{array}$ \\
\hline Prominent "Done" Button & $\begin{array}{l}\text { Located at the end of the visual flow, so that the user } \\
\text { ensures the completion of a certain task. }\end{array}$ & Button "Save" in the creation of relationships. \\
\hline Overview Plus Detail & $\begin{array}{l}\text { Provides an overview of a graphic next to a detailed } \\
\text { view. }\end{array}$ & $\begin{array}{l}\text { Digital representation in the individual view of a } \\
\text { record. }\end{array}$ \\
\hline Datatips & $\begin{array}{l}\text { Gives information about a point of interest in a graphic } \\
\text { in a floating window. }\end{array}$ & $\begin{array}{l}\text { "Map View" section available in some individual } \\
\text { views. }\end{array}$ \\
\hline Dynamic Queries & $\begin{array}{l}\text { Allowing the user to filter the dataset immediately and } \\
\text { interactively. }\end{array}$ & Search results and semantic network view \\
\hline Sortable Table & $\begin{array}{l}\text { The user has the possibility to order the table rows } \\
\text { according to the cell value of the selected column. }\end{array}$ & Table view \\
\hline Forgiving Format & $\begin{array}{l}\text { Allows the user to search for the desired term and } \\
\text { obtain search suggestions of different types. }\end{array}$ & $\begin{array}{l}\text { Simple search box on the homepage - Option } 2 \text {, } \\
\text { and simple search box on the creation of relationships. }\end{array}$ \\
\hline Structured Format & $\begin{array}{l}\text { Provides a set of text fields according to the data } \\
\text { structure to be entered by the user. }\end{array}$ & Some fields available on the advanced search. \\
\hline Input Prompt & Make the interface self-explanatory. & $\begin{array}{l}\text { Search fields on the homepage, on the search results, } \\
\text { and in some sections of the individual views. }\end{array}$ \\
\hline Autocompletion & $\begin{array}{l}\text { Provides a list of search suggestions that automatically } \\
\text { complete the search entry. }\end{array}$ & Simple search box on the homepage - Option 1 . \\
\hline Dropdown Chooser & Allows access to a set of items suitable for a given field. & Advanced search, hierachical browsing, and search results. \\
\hline
\end{tabular}

\section{USER INTERFACE DESIGN}

This section is divided into three subsections that correspond to each proposed scenario. For each scenario, we present the non-functional medium-fidelity mockups created. The presented layouts are close to the final application and contain real content. Visual aspects like color schemes and typography were not studied, since 


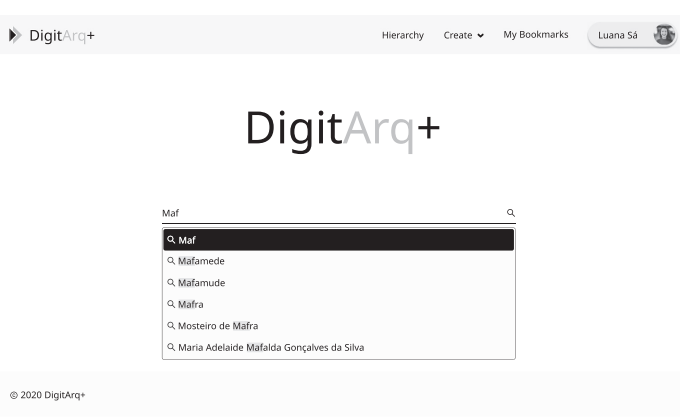

(a) Simple search (Option 1).

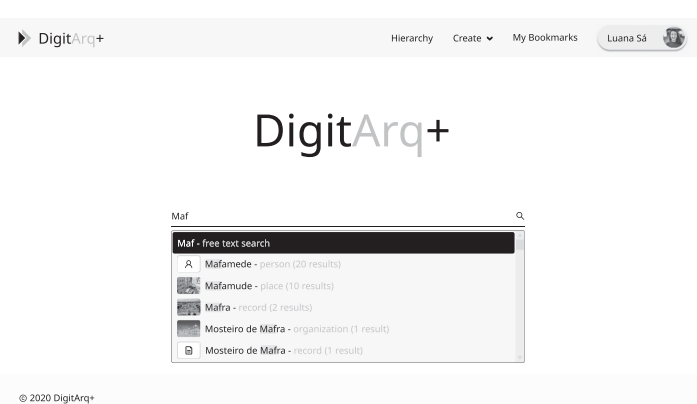

(b) Simple search (Option 2).

Fig. 1. Simple search options.

the focus was on the elements to include in each view. The designation "DigitArq+," visible in the designed mockups, is a temporary name adopted only for the interviews conducted in the evaluation phase of this work.

\subsection{Scenario 1: Search}

We designed three different search solutions: a simple search, based on a standard search bar (see Figure 1); a structured search approach (see Figure 2); and an advanced search solution (see Figure 3). In the simple search, when the user starts typing, a list of search suggestions is shown immediately below the search bar. For this situation, we created two design options. Figure 1(a) presents the first option, where search suggestions only complete the expressions typed by the user. Search suggestions are displayed using autocomplete. Figure 1(b) presents the second option, where search suggestions are also displayed using autocomplete; however, they appear associated with a category and the number of results. The categories available are the following: "Record," "Person," "Institution," "Place," and "Event." The user can also choose not to select any of the suggestions given and perform a free text search.

Alternatively, the user can choose to perform a structured search by clicking on the "Structured Search" link. This type of search, as the name implies, is structured in the sense that it allows the user to search by combining little pieces of information. Search queries are built gradually, according to the choices the user makes regarding the criteria he intends to include in his search. Figure 2 shows the process of building a search query in a more advanced state. As we can infer from the query, the user wants to find the person who was born in 1689 and who signed the Treaty of Utrecht.

Also available to the user is an "Advanced Search" option, shown in Figure 3, which includes filters for each of the available categories: "Description Record," "Conservation \& Restoration Record," "Digital Representation Record," "Person," "Institution," "Place," and "Event." The user can combine filters from different categories if it suits his search purposes. After performing any of these types of search, the user is redirected to the results page. We have created two design options for this page, shown in Figure 4. In option 1, the user can browse the search results in three distinct tabs: "All," "Archival Records," and "Entities," as we can see in Figure 4(a). In option 2, the entities are distributed into individual tabs, as shown in Figure 4(b).

Once on the results page, the user can customize the number of search results visible on each page; sort the results in a variety of ways and in an ascending and descending order; display the results in a list, grid, or map view; refine and improve his search using faceted search; and share and download the results obtained through a link and a spreadsheet generated for both situations, just to name a few features. If the user chooses to search for a place, an event type, or a keyword using the three little search bars on the left, the entered term will be added to the "Active Filters" section on top of the filters and search results. Filters added to the search by clicking on the button on the right side of each search result will also be added to this section. In both images, we can note 


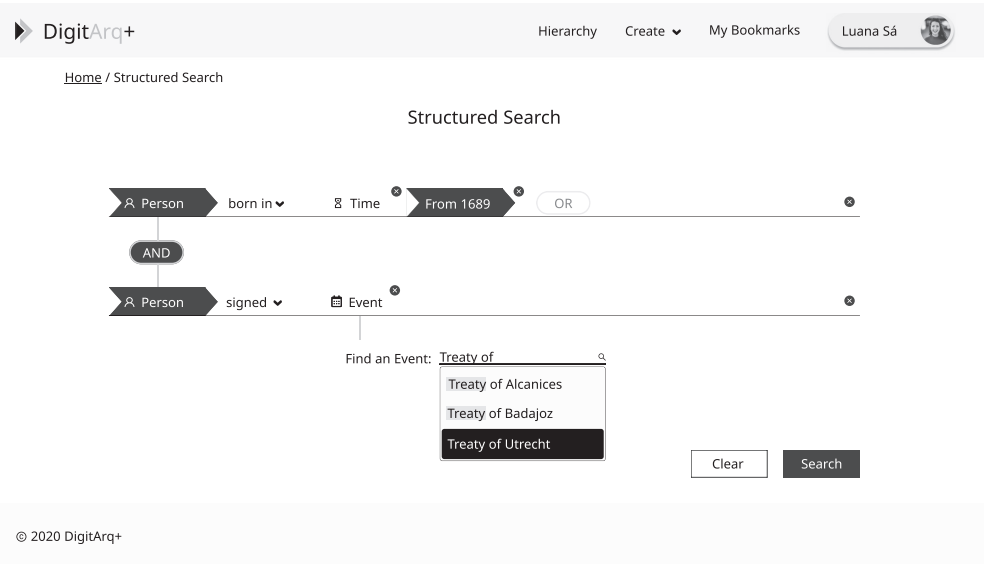

Fig. 2. Structured search.

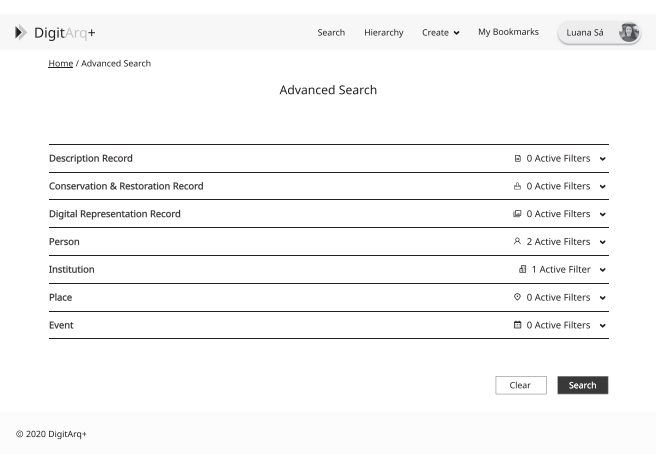

Fig. 3. Advanced search.

that the retrieved resources are within a specific time period (initial and final date filters were applied to search results) and that the Mafra place was also added as a filter to the search (see "Active Filters" section). This filter may have been added through the respective search bar or by clicking on the button next to the Mafra search result.

In order to meet the archivists' mental model regarding the way they structure and organize the documentation, we decided to include an option in the navigation bar that allows users to search for records in a hierarchical structure. A number of features and elements have been added to this structure when compared to the current one. Figure 5 illustrates the page created for this type of search.

\subsection{Scenario 2: Individual View of Description Records and Entities}

The results retrieved from a search can be description records and entities (person, institution, place, and event). The individual views created for a description record, a person, and a place are shown in Figure 6. The individual view of the description record is divided into two parts in order to facilitate the description tasks. This way, the archivist can resize the work space as needed when making a description, having a scrollable area exclusively dedicated to the description content on the left and a fixed area only for the digital representation on the right. The image can be manipulated using the available features. In the content area, the user has the possibility to alternate the description record with the associated conservation and restoration, or support transfer records 


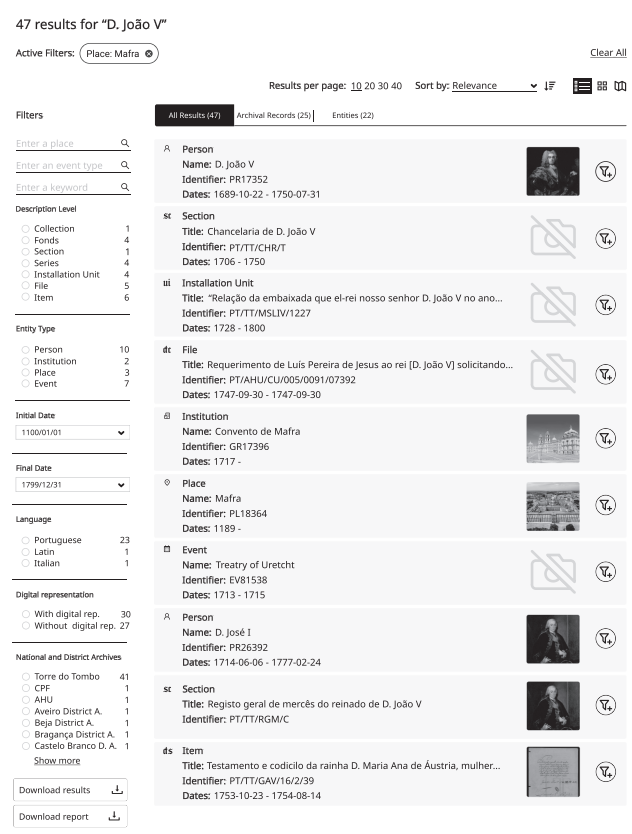

(a) Search results (Option 1).

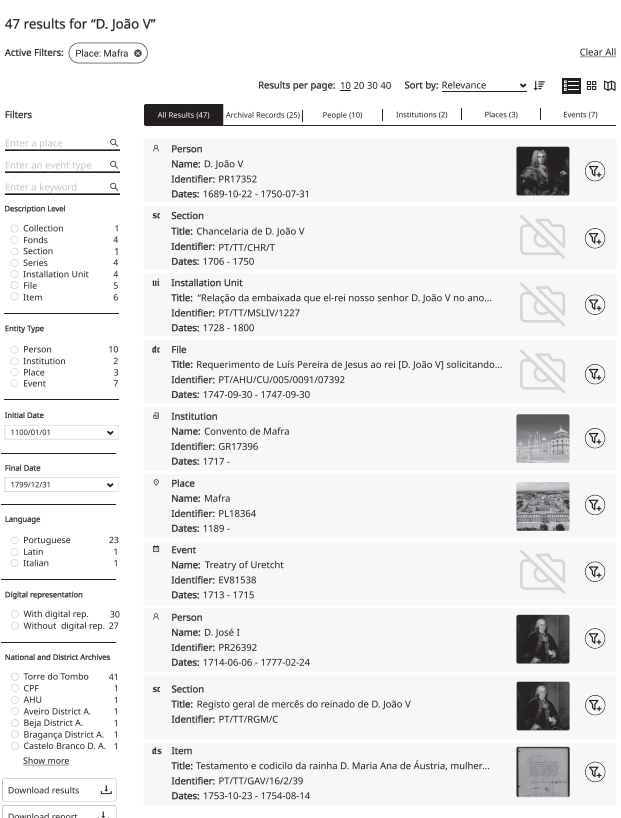

(b) Search results (Option 2).

Fig. 4. Search results options.

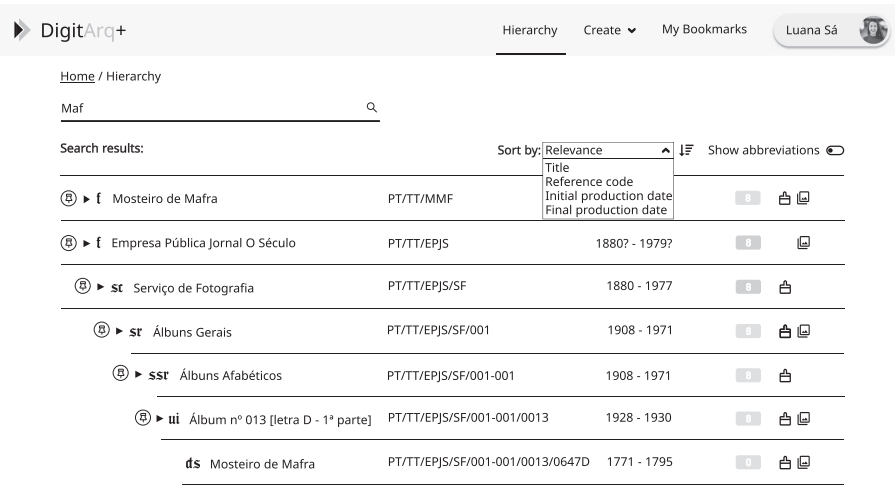

Show more

Fig. 5. Hierarchical browsing.

through the tabs available at the top. The set of metadata fields included were specifically created for the item in question. Also visible is a hierarchy, allowing the user to visualize the position of the record in its hierarchical structure, as well as to navigate and search. Figure 6(a) shows the individual view created for the item "Carta de sentimento do Papa Bento XIV ao rei D. José I sobre o terramoto." 


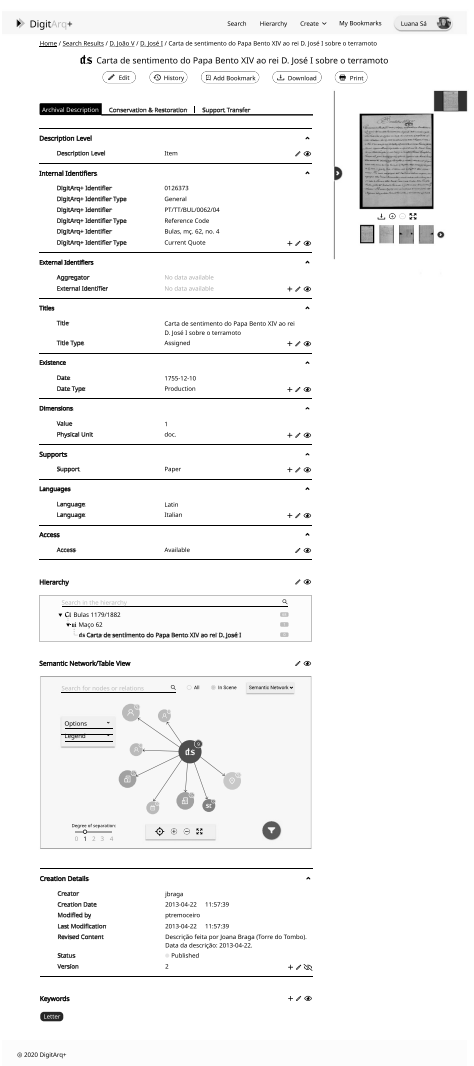

(a) Individual view of a record.

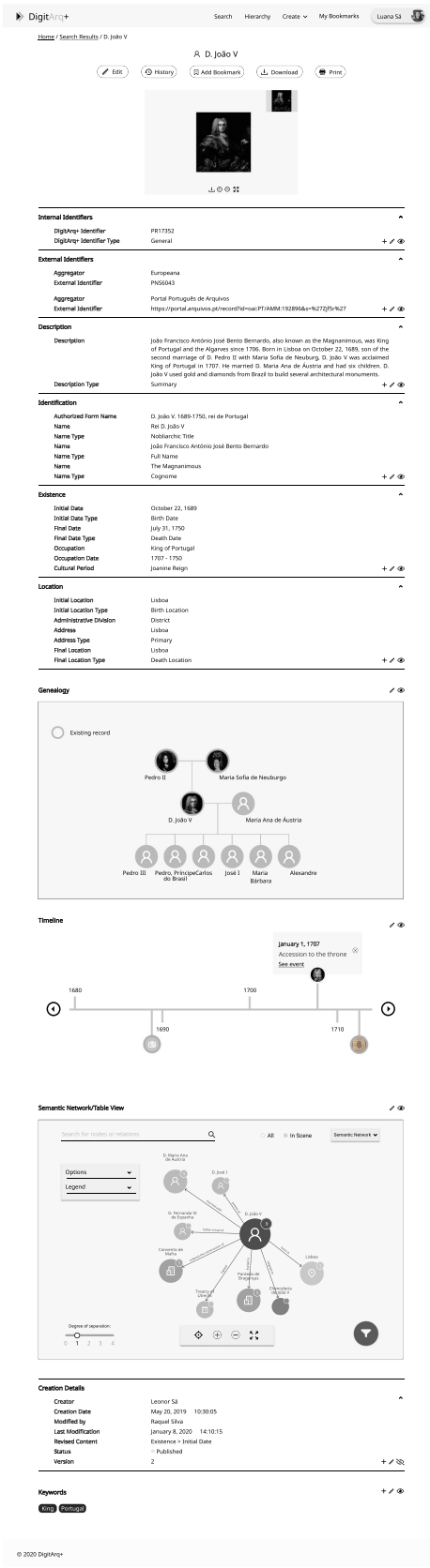

(b) Individual view of a person.

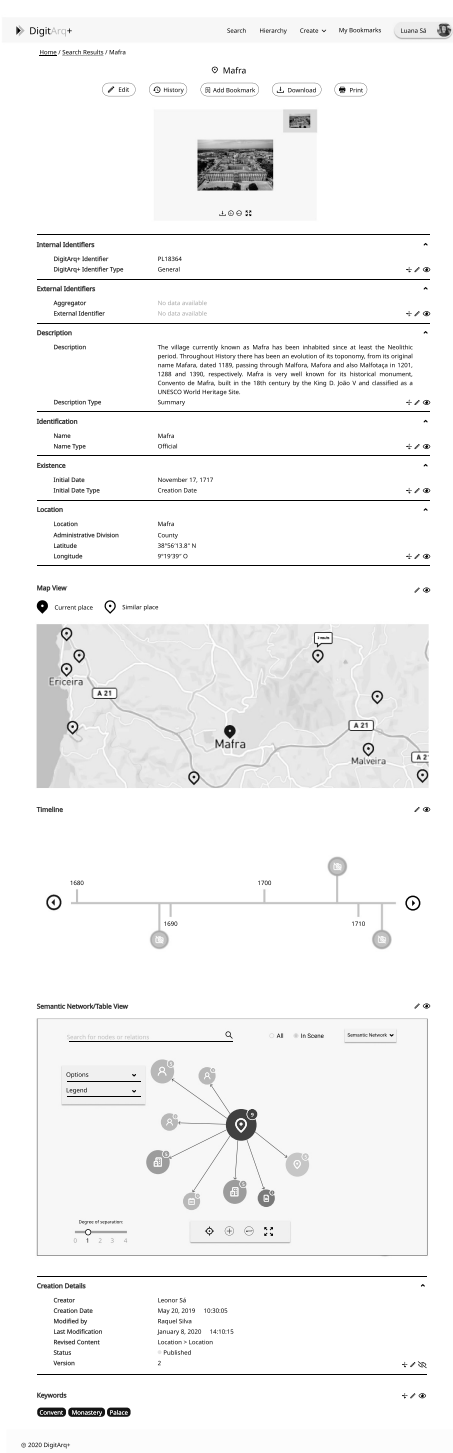

(c) Individual view of a place.

Fig. 6. Individual views. 


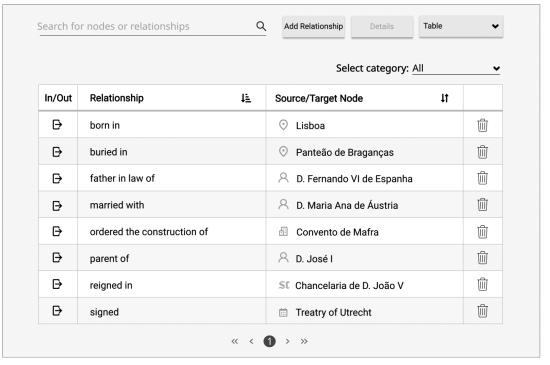

(a) Table view.

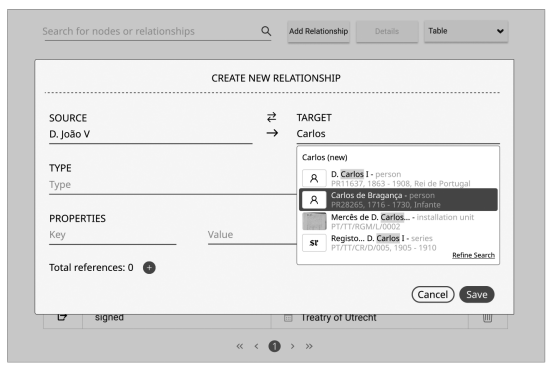

(c) Search for the target node.

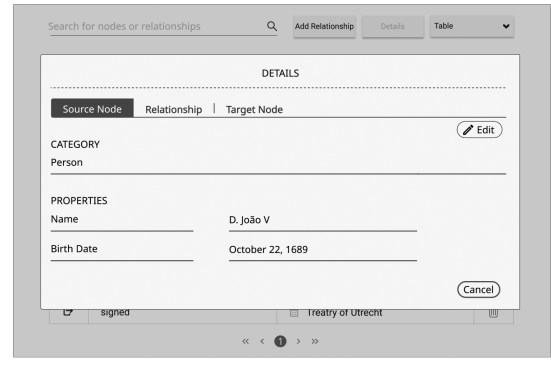

(b) Source node details.

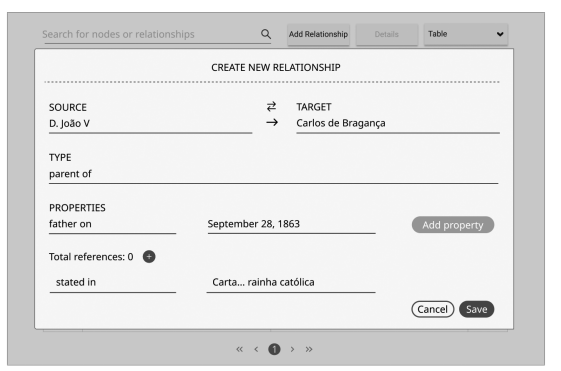

(d) Creation of a new relationship - all fields filled.

Fig. 7. Creation of relationships.

The entities' individual views share a very similar layout; however, they contain some particular elements according to their type: the family tree is exclusive to "Person" entities and the map view is exclusive to "Institution," "Place," and "Event" entities. It is also important to note that each entity has its own metadata fields; however, some of them are similar, since they are suitable for describing different entities. Figures 6(b) and 6(c) show the mockups created for the individual view of a person and place, respectively.

\subsection{Scenario 3: Creation of Relationships}

Common to all individual views (description record and entities), there is a semantic network which allows the visualization of related informational resources, whether they are documents or entities. It offers a set of different features, allowing for better navigation and exploration. These features include search for specific nodes and relationships; view the whole semantic network of the system or only the nodes and relationships directly related to the resource in question; see only the nodes that are at a given degree of separation; center, zoom in, zoom out, and expand the view; as well as apply filters to the nodes and relationships visible. By selecting a node, the user can hide it, expand all or certain related nodes, access its individual view, and view its properties. Figure 7 shows the mockups created for this scenario. From the semantic network view, the user can switch to a table view, shown in Figure 7(a), where he can also see the nodes and relationships they establish with each other. The content of the table can be sorted by column. It is possible to see the details of the existing relationships (details about the source node, the relationship, and the target node), Figure 7(b), and create new relationships involving the current node, which can be a document or an entity. The interface for creating new relationships includes the possibility to change the direction of the relationship, autocomplete and disambiguation features, allowing one to search the target nodes more accurately, as we can see in Figure 7(c)-the specification of the type of relationship and its properties, and the possibility to add references that support the relationship being created. After creating the relationship, a new line with the newly created relationship will appear at the top of the table and if the user returns to the semantic network view he can see the relationship added to the semantic 
network. The possibility to create new relationships was only included in the table view since the semantic network view proved to be more useful for browsing over informational resources.

\section{EVALUATION}

This section describes the evaluation process followed to gather feedback on the proposed solutions. For such, we conducted remote interviews with archival professionals supported by an introductory video and a survey with open- and closed-ended questions. The results obtained were analyzed using both quantitative and qualitative methods, as described in Section 6.

\subsection{Survey}

The developed survey is comprised of 4 questions about demographic data, 30 questions distributed across our 3 scenarios of interest and 3 questions that contemplate final considerations. These questions have different formats with only two or five answer options, using a Likert scale for the latter. This scale allows participants to assess their satisfaction by measuring their opinions on scales of agreement or disagreement, importance, and potential for use. A question for selecting concepts with the possibility to add a new option was also included. In order to demonstrate how user interaction with structured search and relationship creation works, we created two demonstrating videos. These videos were shared with users before the sessions. In order to test the evaluation setup, we conducted preliminary remote pilot sessions with five volunteer members of the EPISA project.

\subsection{User Evaluation Sessions}

Participants were carefully recruited for the purpose of the study in question. Thus, only archival professionals were selected from four different categories: director, archivist, curator, and administrator. Being familiar with the EPISA project and LD systems was not a selection criteria, since we wanted to assess the receptivity of the participants toward a new system based on a new description model. Our goal was to test the solutions created with a diverse sample of participants in terms of occupations and institutions (i.e., archives). Our study involved 20 participants from a total of 14 archives.

In order to schedule the planned sessions, we sent a message to 20 potential participants, starting by briefly presenting the researcher responsible for the study, followed by an explanation of the context in which the study is developed, and information related to the approximate duration of the session (between 60 and 90 minutes), and ended with the requirements needed for the session. The requirements were the following: computer or other device with microphone and Internet access; access to the Zoom videoconference platform or an alternative suggested by the participant; screen sharing; and visualization of an introductory video before the session. The recording of the session was not included in the requirements previously listed, as it was not mandatory for the completion of the session, despite having advantages in the subsequent analysis of the feedback collected. In case the participants agree with the recording of the session, they had to accept the informed consent form also prepared to ensure confidentiality regarding data protection and privacy.

As preparation for the session, we sent an introductory video to the participants in which we presented an overview of the project, the goal of the study, and the medium-fidelity mockups developed. We also prepared an interview script to be followed by the moderator throughout the sessions. This allowed the replication of the sessions, ensuring the reliability and consistency of the results [14]. The sessions consisted of structured interviews based on the questions that comprise the survey, which were read by the participant. Despite being considered structured interviews, the moderator had the flexibility to introduce other questions in order to understand some less well-clarified aspect or to deepen a certain subject. Using the think-aloud protocol [7], the participants were invited to verbalize their thoughts in each question, regardless of their nature, in order to collect as much feedback as possible. To save time, participants did not write their answers to the open-ended questions, unless they have not accepted the recording of the session. Figure 8 synthesizes the interactions between the moderator and the participant. 


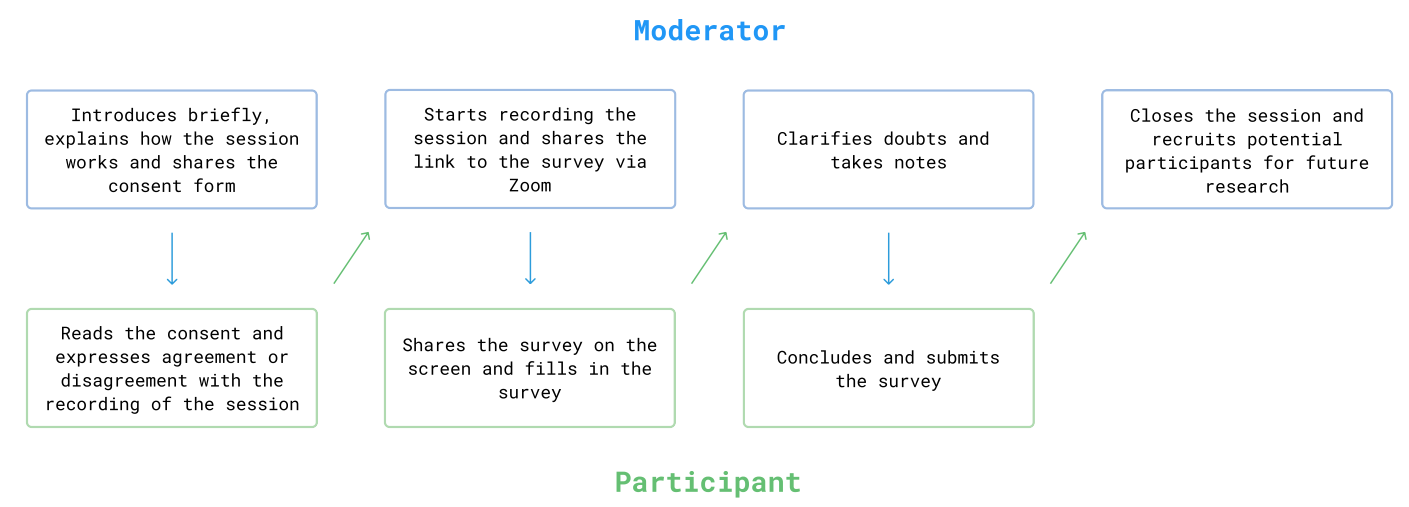

Fig. 8. Interview procedure.

\section{DATA ANALYSIS}

In this section, we present the analysis of the results obtained from the evaluation sessions. We start by characterizing the sample of participants, then we expose the approach followed for the qualitative analysis and present our findings grouped by scenario, combining the results of the quantitative analysis to the closed-ended questions, with the results obtained through the qualitative analysis of the open-ended questions. In some closed-ended questions, comments or suggestions mentioned by the participants were grouped. The last three open-ended questions are then analyzed, providing an overview of the impact caused by the use of LD in the archival domain.

\subsection{Demographic Data}

All participants are over 39 years old and the majority are aged between 40 and 49 years old (11 participants, $55 \%)$. The sample is distributed equally between the female and the male gender. Regarding the participant's occupation, 2 of the 20 participants are archive directors, 11 are archivists, 5 assume both the functions of director and archivist, 1 is a curator, and the last one performs the role of administrator.

\subsection{Qualitative Analysis Approach}

To perform the qualitative analysis of the collected data from the open-ended questions, we conducted a thematic analysis [1]. Thematic analysis is a method that provides a way to identify, analyze, and describe patterns of meaning in data, also called "themes," which are seen as similar ideas or concepts reported by participants in a given study. These themes are useful for structuring and understanding participants' opinions, perceptions, and experiences shared during the interviews. Given the nature of our study, we used a combination of inductive and deductive approaches in the data analysis, allowing the themes to emerge from the data, but also considering preconceived themes based on literature review, research questions, and knowledge acquired throughout the development of this work. We also followed a semantic approach, focusing our analysis on the explicit content of the collected data. We conducted the data analysis using Braun and Clarke's framework [4], being the work developed in each of its six steps, specifically: Phase 1: Familiarize with the data, Phase 2: Generate initial codes, Phase 3: Search for themes, Phase 4: Review themes, Phase 5: Define themes, and Phase 6: Write-up. Although these steps are described in a certain order, the framework is flexible, meaning that we can revisit or advance steps in the analysis process, if necessary.

\subsection{Scenario 1: Search}

In this section, we explore the results obtained in the open- and closed-ended survey questions related to the search scenario. Regarding simple search, $75 \%$ of the participants (15) preferred the simple search option that 
Table 4. Filter Suggestions for Advanced Search

\begin{tabular}{ll}
\hline Filter category & Filter suggestions \\
\hline \multirow{2}{*}{ Description Record } & $\begin{array}{l}\text { Search at a specific description level; } \\
\text { Available/Unavailable; Search in a specific archive; } \\
\text { Holding entity; Quota; Record creator; } \\
\text { Author/Producer in the case of a collection }\end{array}$ \\
Identifier; Intervention description field; Type of \\
intervention performed (e.g., re-binding, microfilming, \\
exporting from a legacy database to a new database) \\
Digital Representation Record \\
$\begin{array}{l}\text { Available/Unavailable; Title; Technical information } \\
\text { about the digital object and transferable formats, as } \\
\text { well as the space occupied; Digital object reuse rules } \\
\text { Institution }\end{array}$ \\
$\begin{array}{l}\text { Differentiate the location in relation to the contact } \\
\text { address, the headquarters; in other words, any } \\
\text { subdivision of the entity }\end{array}$ \\
\hline
\end{tabular}

presented a set of categorized suggestions and the associated number of results. The mockups created are presented in Figures 1(a) and 1(b). Regarding structured search, most of the participants (15) expressed satisfaction with the structured search; however, some acknowledged the need to know the functioning of the system and to explore a functional version of this search approach to be able to give suggestions. One of the participants expressed inclusion concerns, suggesting the introduction of voice searches. Figure 2 shows one of the mockups created for this type of search.

Regarding advanced search, most participants considered the presence of more elaborate filters for categories to be very important. However, some participants also mentioned the need to acquire experience to deal with the high number of filters that this search offers, in order to obtain results that satisfy their information needs. Some participants indicated filters potentially relevant for the recovery of a description and conservation and restoration records, a digital representation, and an institution. Table 4 synthesizes these suggestions by category. An interesting aspect pointed out by one of the participants regarding the events is the lack of adequacy of the use of a controlled language in some epoch concepts, as they cannot be transposed to the present, which can make it difficult to retrieve information. More general suggestions were also indicated. Some examples were the inclusion of an appraisal module related to actions on documents, for instance, their elimination, their conservation and associated period of time, and the names of the entities responsible for these decisions; an acquisition module related to the transparency of the acquisition of information resources by incorporation, by purchase, at what cost, if any, among others. Figure 3 presents the mockups created for the advanced search.

Regarding hierarchical browsing and specifically the new features proposed, we can state that direct navigation in the hierarchy, the signaling of the existence of an associated digital representation, and sort by initial production date were considered the most relevant. The features related to the number of records inside a specific description level and the signaling of the existence of an associated conservation and restoration registered the largest number of preferences with the degree of importance. Figure 5 shows the mockup created for this search approach. Table 5 summarizes some of the results obtained for the structured search, the advanced search, and the hierarchical browsing.

Participants also indicated the context scenarios in which the search approaches presented were particularly useful. These are summarized in Table 6 in decreasing order for each search approach. 
Table 5. Results Related to the Proposed Search Approaches

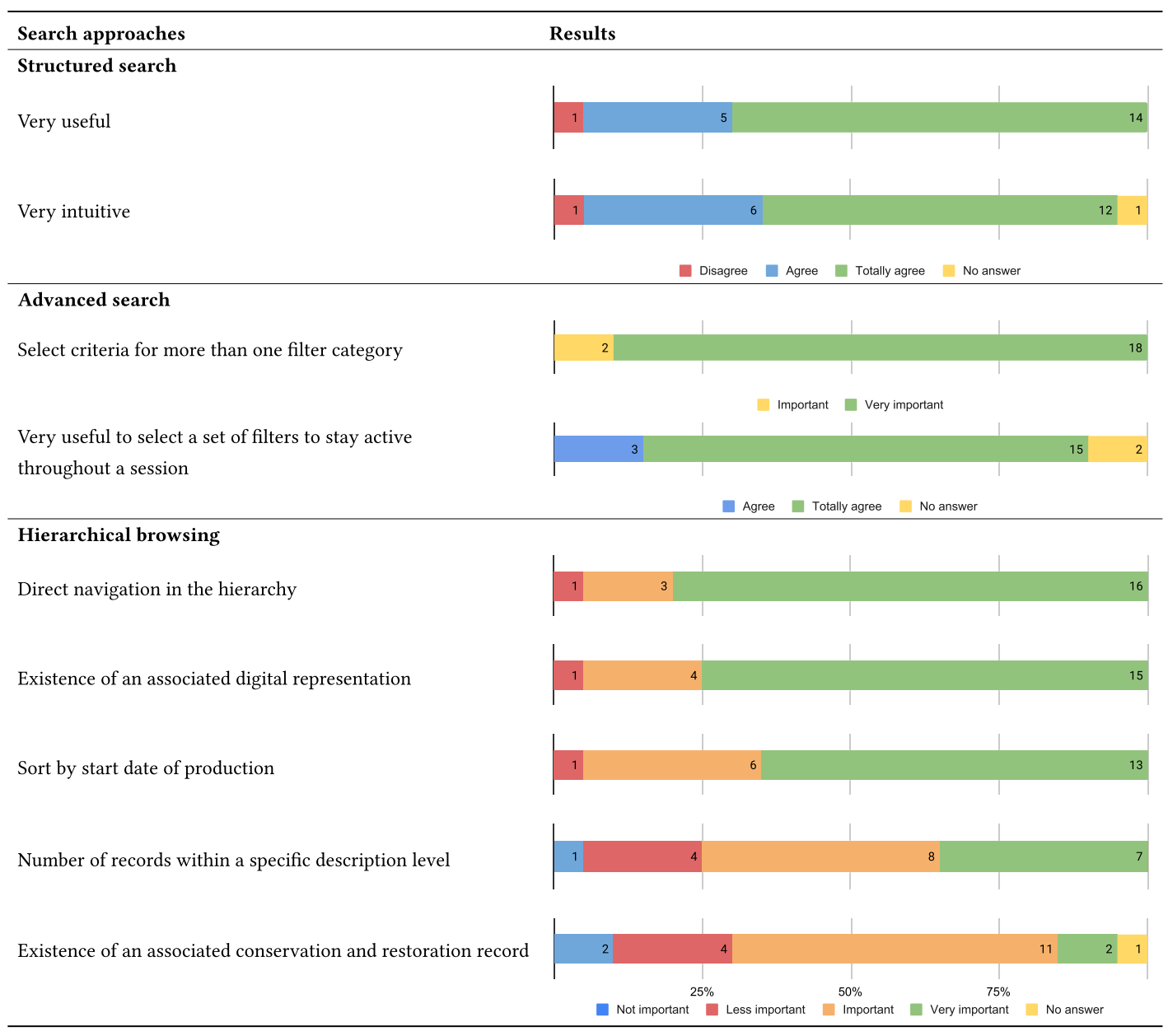

Regarding the visualization of search results, and taking into account the options created for the search results tabs, the participants were equally divided between option 1 (see Figure 4(a)), where the entities were presented in a single tab, and option 2 (see Figure 4(b)), where each entity had its own table. The participants who selected option 1 reported that the aggregation of the entities in a single tab would allow the discovery of new knowledge, pleasing them with the idea of being surprised with the results obtained. In option 2, since the entities are divided into individual tabs, participants who preferred this option considered that this distribution would facilitate the performance of a more focused search. The filters applied to the search results were considered by most participants to be very important. Choosing the language proved to be of little importance for five participants. One participant drew attention to the importance of language equivalence from a taxonomical point of view; for example, in the case of the filter related to the description level, which is essential to maintain interoperability with current archives and document management systems. Regarding the "Support" filter, participants mentioned that it should constitute a taxonomy, i.e., a controlled vocabulary, in order to allow the correct identification of the intended support. Table 7 contains other results related to the visualization of search results. Refer to Figure 4 to see the mockups associated. 
Table 6. Context Scenarios for Search Approaches

\begin{tabular}{ll}
\hline Search approaches & Context scenarios \\
\hline & When the location of a document or occurrence is unknown. \\
& When the archive is not well known. \\
& Search for something not quite defined. \\
Simple search & Search for something known. \\
& Search for any variant of something. \\
& Perform a more comprehensive search. \\
& Know the number of occurrences. \\
& Make scripts. \\
\hline \multirow{5}{*}{ Structured search } & Combine multiple filters. \\
& Perform a focused search. \\
& Locate informational resources. \\
& Search for something not quite defined. \\
\hline & Search for something well defined. \\
& Search for passport and parish records. \\
& Search for concrete description levels. \\
& Identify relationships. \\
Advanced search & Refine the search. \\
\hline Hierarchical browsing & Perform a search focused on the type of documentation. \\
& Improve simple exploratory searches. \\
& Perform a search focused on the producer. \\
\hline
\end{tabular}

Table 7. Results Related to the Visualization of Search Results

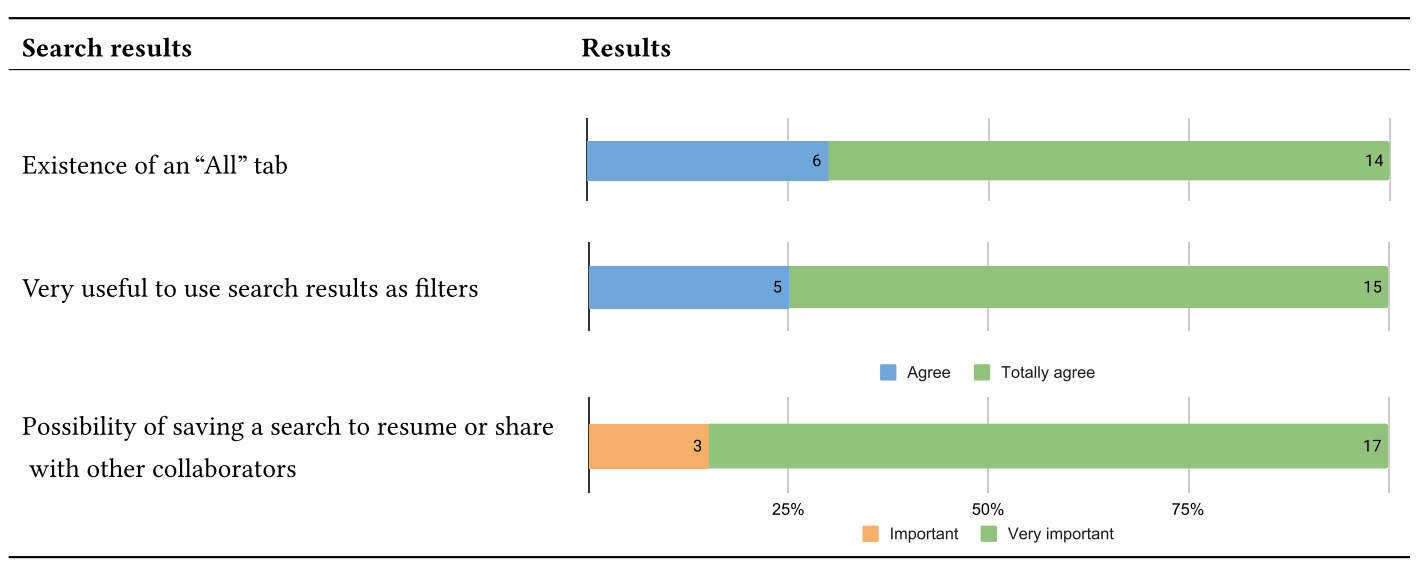




\subsection{Scenario 2: Individual View of Description Records and Entities}

This section comprises the results for the closed-ended questions about the individual view of description records and entities. Regarding the concepts that could be associated with the individual views, all options presentedDescription Unit, Conservation and Restoration Intervention, Support transfer, Person, Institution, Place, and Event-were selected by at least 12 participants. Other views were also suggested by the participants: author, functions, and a management and report view. The mockups created for the individual views of a description record, a person, and an institution are presented in Figure 6.

The "External Identifiers" section was introduced in the various views, allowing the creation of bridges between different information repositories, such as in Europeana-14 participants considered the existence of this section very important, 5 considered it important, and only 1 participant considered it less important. Another question allowed us to conclude in which views it is important to include a timeline of important events. The results inform us that the majority of participants (16) considered the presence of this timeline very important in the pages related to a person and an institution.

The existence of a semantic network view in all individual views was considered very important by most participants. Our results also revealed that all the functionalities made available in the semantic network view obtained the mention of very good, attributed by at least 10 participants. One of the participants commented in this question the importance of exporting this visualization, for example, to document a study. It was also mentioned the inclusion of other multidimensional visualizations; for example, to see the evolution of the relationships shown in the graph through a flowchart or an animation.

The existence of a genealogy element associated with the person was considered very important by most participants. Some participants mentioned the usefulness of a family tree in the case of organizations, one of whom also suggested the existence of a timeline associated with the family tree, which would allow a set of documents to be related to a set of events. He also referred to the importance of the family tree not only being composed of isolated photos, but also including a set of filters in order to allow the discovery of new relationships.

Most of the participants gave maximum importance to the presence of a map in the individual view of an organization, a place, and an event, followed by the ranking. A small number of participants gave little importance to the presence of a map on the application pages from the perspective of an internal user, but very useful from the perspective of an external user. Some participants mentioned that it would also be a possibility to include a geo-referenced visualization in a person's individual view, being able to represent the different places where she performed some important activities throughout her life. The presence of the map, combined with other features such as the ability to search a specific location on the map, was also mentioned as a useful feature.

\subsection{Scenario 3: Creation of Relationships}

In this section, we analyze the results obtained for the closed- and open-ended questions related to the solution designed for the creation of relationships. Figure 7 shows the mockups created for this scenario.

Half of the participants expressed their satisfaction with the elements presented for the creation of relationships while others recognized the need to explore the mechanism. Refer to Figure 7(d) to see the associated mockup. One of the participants suggested the addition of the following elements: identification of the information source as internal or external and identification of relationships with a low level of reliability that will later be validated for future user access. Another participant referred that the creation of relationships should be in accordance with the RiC standard. The bonds of the relationships created should be from one to many. He also said that although the properties are normalized according to CIDOC-CRM, it would be important for the archival description to identify the $\mathrm{RiC}$ resource and create rules according to this standard that are flexible since this standard is still in its first version.

Most participants said they were satisfied with the solution presented for the ambiguity (see Figure 7(c)), while others stated the need to explore the presented proposal. Few participants contributed with the following suggestions: possibility to identify, for each node, the number of relationships registered in the information system, 
Table 8. Results Related to the Creation of Relationships

\begin{tabular}{ll|l|l|l|}
\hline Creation of relationships & Results \\
\hline Very intuitive & & & \\
\end{tabular}

allowing one to validate whether the relationship being created is consistent with the existing relationships and identify the affiliation and place of residence, for example, in the case of a person. Table 8 contains other results related to the solution presented for the creation of relationships.

\subsection{Final Considerations}

This section analyzes the open-ended questions where the participants made some final considerations about the use of LD in archives. Almost all participants (17) stated they were in favor of the adoption of a system with the characteristics presented. Only three participants pointed out the need to explore the prototype in order to give an affirmative answer. We also received the following suggestions from two participants: access materials from other countries; export in multiple formats such as XML and RDF, as proof of scientific work that allows the replicability of a study; and enable resource citability automatically. We also collected the following more general suggestions: use on multiple devices, fixed or mobile, allowing one to make descriptions on the field, by creating a QR code automatically; have a productivity dashboard to obtain performance data from individual and collective description; have an audit trail that allows the visualization and the recovery of previous versions; and use the "tab" key to switch between description fields, instead of using the mouse. This last aspect was mentioned as a facilitator of the description activity, increasing comfort and productivity.

In general, we can conclude that the participants regain advantages of using LD in their activities and consequently for the external public. However, they admitted having the need to experiment with a functional version to be able to give a more grounded opinion on some questions. This functional version should contain a significant number of information resources so that the tests are as close as possible to the users' reality. Finally, we emphasize the great openness to change witnessed by the vast majority of participants.

\section{CONCLUSION}

The work presented here allowed us to investigate solutions for user interaction in three scenarios: search, individual record view, and relationship creation. In this section, we highlight the main conclusions, structured in these three contexts. 
Considering the relevance of the proposed search approaches, we can conclude that the advanced search is the one that reveals the most potential for use, followed by the structured search. This latest search consists in a new and innovative search approach that we found in interfaces that take advantage of both the CIDOC-CRM standard and the RiC standard. In regard to the simple search and the hierarchical browsing, the first proved to be the one with least potential for use. Thus, in decreasing order of potential of use, we have advanced search, structured search, hierarchical browsing, and simple search.

Considering the presentation of search results, the majority of participants totally agreed with the existence of an "All" tab containing all the results retrieved by a search and the remaining participants simply agreed. As for the distribution of results in tabs, half of the participants found it more useful to aggregate all types of entities retrieved in a single tab and the other half considered it more useful to aggregate the results of each entity in individual tabs. Thus, these results do not allow us to conclude which of the options presented is most useful for the activities of an archivist. However, quite interesting reasons were pointed out that supported each of the choices.

Considering the use of filters in the search process, we were able to conclude that all the filters presented in the search results were considered very important by the majority of participants. Sorting them in descending order of importance, we have start date and end date, place, type of event, digital representation, type of entity, level of description, keyword, language, and national and district archives. Other filters were also indicated as relevant to narrow down the search results.

Considering the importance of the elements included in individual views, we have to consider the elements that are common to all created views and the elements that are specific to some of them. In the first case, the section with external identifiers was considered of great importance, as only one participant considered it to be of little importance. The timeline of important events revealed its importance in descending order, as follows: individual view of a person and an institution, individual view of an event, individual view of a place, and individual view of a record. The semantic network view was considered very important or important by the vast majority of participants, in the following decreasing order: individual view of a person, individual view of an institution, individual view of an event, and individual view of a place. The presentation of a map in the different views was considered a relevant element to include in each of the entities. In the second case, we can mention that the family tree included in the individual view of a person was considered to be of great importance, with only one participant giving little importance to this element. In summary, we can conclude that none of the elements presented should be discarded.

Considering the value of the solution presented for creating relationships, all participants agreed or fully agreed that the proposed solution for the creation of relationships was very intuitive. We gathered two new elements that were suggested by one of the participants-identification of the source of information as external or internal and identification of relationships with a low level of reliability that will later be validated for future user access-and a suggestion to follow the RiC standard on how to create relationships. The creation of relationships in both directions was an aspect considered of great importance for all participants, as well as the possibility to add all known references that support a given relationship. The solution presented for the precise identification of the target node deserved the satisfaction of most participants. The number of relationships established by each node was mentioned as an important aspect in validating the consistency of new relationships. For the disambiguation of suggestions associated with people, the inclusion of the affiliation and place of residence was also pointed out as a possible solution.

Finally, we are able to assess the impact of introducing LD concepts in archival management systems considering the feedback of our participants, in terms of opportunities, advantages, challenges, and problems. This impact is summarized next for each referred topic.

Opportunities. The following opportunities were highlighted: improvement of the quality of information and representation of the information produced; improvement of the data recovered in terms of search; detection of 
gaps and identification of new ways of improving/qualifying the archival records; more effective description for internal and external users; and faster description using lists of controlled terms, atomizing the information.

Advantages. The following advantages were recognized: access to related information, quality and reliable information.

Challenges. The following challenges were mentioned: adaptation to a new way to process the archival descriptions; evolution of the current structures to a semantic-based model; and the adoption of a model developed in the context of museums that may not meet the specific needs of the archives.

Problems. The following problems were identified: reduction of productivity; critical aspects of investment; and the fact that some archives do not have sufficient processed data to take advantage of the potential offered by the new LD paradigm.

In conclusion, the adoption of a system with the characteristics presented would be well accepted by most participants consciously, while others revealed the need to try a functional version in order to assess the real impact in their professional activities. The results of this work allow us to generalize the impact of the introduction of LD concepts for any archival management system. As future work, we should consider the suggestions given by the participants in the sessions performed on the last phase of the developed work and then improve the design by creating high-fidelity prototypes. The next step would be the creation of a functional prototype with a database loaded with a significant number of records of various types, allowing one to simulate the working environment of the archival professionals in a paradigm dominated by LD. This prototype could be evaluated through usability tests. A set of different tasks would be proposed to the participants who would be observed directly while interacting with the system, allowing one to evaluate the efficiency, effectiveness, and user satisfaction with the prototype presented.

It is important to note that the work developed did not intend to create a definitive interface to visualize and interact with LD in historical archives, but rather to contribute with possible solutions for such, tested with end users. The solutions presented were based on the study of several existing systems, some of them still under development and subject to iterations, also according to studies carried out with users. Thus, the result of this work may serve as a starting point for a broader study in terms of interaction design patterns to be applied to interfaces for interacting with LD in different areas, always supported by user studies.

\section{ACKNOWLEDGMENTS}

A word of thanks to Dr. Francisco Barbedo, who, although no longer with us, remains an example of professionalism, dedication, and enthusiasm for the world of archives and its constant innovation. To all the archival professionals who participated in the interviews, thank you for the availability, kindness, shared experiences, and thoughts. Finally, we would also like to thank the reviewers for their careful review of our article, and comments and suggestions given that contributed significantly to improve and clarify some aspects of this article.

\section{REFERENCES}

[1] Philip Adu. 2019. A Step-by-step Guide to Qualitative Data Coding. Routledge, London.

[2] ACM. Association for Computing Machinery: Advancing Computing as a Science \& Profession. Retrieved from http://www.acm.org/.

[3] Tim Berners-Lee. 2009. Linked Data. Retrieved April 19, 2021 from https://www.w3.org/DesignIssues/LinkedData.html.

[4] Virginia Braun, Victoria Clarke, and Paul Weate. 2016. Using thematic analysis in sport and exercise research. Routledge Handbook of Qualitative Research in Sport and Exercise (Sep. 2016), 191-205. https://doi.org/10.4324/9781315762012

[5] Philip K. Carlisle, Ioannis Avramides, Alison Dalgity, and David Myers. 2014. The Arches Heritage Inventory and Management System: A Standards-Based Approach to the Management of Cultural Heritage Information. Technical Report. English Heritage, World Monuments Fund, and the Getty Conservation Institute.

[6] H. Frank Cervone and Lars G. Svensson. 2015. Linked Data and User Interaction. De Gruyter Saur, Berlin,. https://doi.org/10.1515/ 9783110317008 
[7] Elizabeth Charters. 2010. The use of think-aloud methods in qualitative research an introduction to think-aloud methods. Brock Education: A Journal of Educational Research and Practice 12 (July 2010), 68-82. https://doi.org/10.26522/brocked.v12i2.38

[8] Alan Cooper, Robert Reimann, David Cronin, and Christopher Noessel. 2014. About Face: The Essentials of Interaction Design (4th ed.). Wiley Publishing, New York.

[9] DGLAB. 2021. Direção-Geral do Livro, dos Arquivos e das Bibliotecas. Retrieved from https://dglab.gov.pt/.

[10] Thomas Francart. 2021. Sparnatural. Retrieved from http://labs.sparna.fr/sparnatural-demo-dbpedia/.

[11] CIDOC CRM Special Interest Group. 2020. CIDOC CRM. Retrieved from http://www.cidoc-crm.org/.

[12] Sébastien Heymann, David Rapin, and Jean Villedieu. 2020. Linkurious. Retrieved from https://inkurio.us/.

[13] ICA. 2016. International Council on Archives. Retrieved from https://www.ica.org/.

[14] Jonathan Lazar, Jinjuan Heidi Feng, and Harry Hochheiser. 2017. Experimental design. In Research Methods in Human Computer Interaction (2nd ed.), Jonathan Lazar, Jinjuan Heidi Feng, and Harry Hochheiser (Eds.). Morgan Kaufmann, Boston, 45-69. https: //doi.org/10.1016/B978-0-12-805390-4.00003-0

[15] Eric Lease Morgan. 2014. Linked Archival Metadata: A Guidebook. Technical Report. University of Notre Dame.

[16] Dunia Llanes-Padrón and Juan-Antonio Pastor-Sanchez. 2017. Records in contexts: The road of archives to semantic interoperability. Program 51 (Nov. 2017), 387-405. https://doi.org/10.1108/prog-03-2017-0021

[17] Travis Lowdermilk. 2013. User-Centered Design: A Developer's Guide to Building User-Friendly Applications. O’Reilly Media, Inc., Newton, MA.

[18] Carlo Meghini, Franco Niccolucci, Achille Felicetti, Paola Ronzino, Federico Nurra, Christos Papatheodorou, Dimitris Gavrilis, Maria Theodoridou, Martin Doerr, Douglas Tudhope, Ceri Binding, Roberto Scopigno, Andreas Vlachidis, Julian Richards, Holly Wright, Guntram Geser, Sebastian Cuy, Johan Fihn, Bruno Fanini, and Hella Hollander. 2017. ARIADNE: A research infrastructure for archaeology. Journal on Computing and Cultural Heritage 10 (Aug. 2017), 1-27. https://doi.org/10.1145/3064527

[19] British Museum. 2019. ResearchSpace. Retrieved from https://www.researchspace.org/.

[20] British Museum. 2021. The British Museum. Retrieved from https://www.britishmuseum.org/collection.

[21] Jinfang Niu. 2016. Linked data for archives. Archivaria 82, 1 (Dec. 2016), 83-110.

[22] Dominic Oldman and CRM Labs. 2014. The CIDOC Conceptual Reference Model (CIDOC-CRM): PRIMER. Technical Report. British Museum. http://www.ics.forth.gr/.

[23] Dominic Oldman and Diana Tanase. 2018. Reshaping the knowledge graph by connecting researchers, data and practices in researchspace. In The Semantic Web - Proceedings of the 17th International Semantic Web Conference (ISWC'18), Part II, Lecture Notes in Computer Science, Vol. 11137. Springer, Cham. https://doi.org/10.1007/978-3-030-00668-6_20

[24] Laura Po, Nikos Bikakis, Federico Desimoni, and George Papastefanatos. 2020. Linked Data Visualization: Techniques, Tools, and Big Data. Vol. 10. Morgan \& Claypool, San Rafael, CA. https://doi.org/10.2200/S00967ED1V01Y201911WBE019

[25] Arches Project. 2021. Arches. Retrieved from https://www.archesproject.org/.

[26] Bernhard Schiemann, Martin Oischinger, and Günther Görz. [n.d.]. Erlangen CRM/OWL. Retrieved from http://erlangen-crm.org/.

[27] Ed Summers and Dorothea Salo. 2013. Linking Things on the Web: A Pragmatic Examination of Linked Data for Libraries, Archives and Museums. arXiv:1302.4591. Retrieved from http://arxiv.org/abs/1302.4591.

[28] Jenifer Tidwell. 2010. Designing Interfaces. O’Reilly Media, Inc., Newton, MA.

Received November 2020; revised September 2021; accepted September 2021 